\title{
Tecnología para una economía nacional
}

\author{
Francisco Javier Ibisate
}

El motivo de las siguientes reflexiones nace de una pregunta que no pocas personas comienzan a plantearse: ¿es viable la economía salvadoreña? Los motivos explícitos o implícitos de la pregunta son diversos y al mismo tiempo interrelacionados. No será viable nuestra economía si el anunciado crecimiento no va acompanado de una sensible equidistribución social. No hay desarrollo sin crecimiento, pero un crecimiento sin equidistribución no es desarrollo. El Foro de Concertación busca ensamblar estos dos términos, al mismo tiempo que el Plan de Reconstrucción Nacional muestra lo lejos que hemos estado de estos objetivos. Alguna conclusión beneficiosa deberíamos sacar de la triste guerra.

Una segunda razón, al preguntarnos por la viabilidad de nuestra economía, es reconocer nuestra vocación centroamericana, sin la cual no queda mucha capacidad de un crecimiento sostenido. Lo reducido del territorio nacional, la relativa escasez de recursos naturales sumado al deterioro ecológico causado por la guerra, la presión demográfica de una población laboriosa que quiere pero que no encuentra dónde trabajar y emigra por cientos de miles al exterior, nos lleva a transcender las fronteras y los nacionalismos impropios de un mundo organizado en mercados comunes. Hay que respetar las fronteras precisamente porque no tienen ninguna importancia. Esta línea de pensamiento está presente en las siguientes reflexiones.

Hay también un tercer elemento que amenaza al crecimiento interno, sin el cual no habrá ni paz ni desarrollo. Se trata de nuestra deficiente tecnología productiva, que de manera especial se resiente al preferenciar un modelo de desarrollo hacia fuera y que se traduce en una interna- 
lización de la producción extranjera en nuestro mercado. Esta tercera dimensión será el tema principal del presente comentario. Con el desmantelamiento de la protección arancelaria y la penetración de la tecnología extranjera, ¿podremos mantener una economía nacional? El Dr. Joseph Hodara, consultor de la CEPAL y asesor de nuestro gobierno para el Programa Nacional de Ciencia y Tecnología, plantea, a modo de ultimátum, el desafío de la tecnologia:

Los países que no se adapten a las nuevas modalidades verán comprometida su viabilidad como entidades nacionales y económicas (Hodara, 1992).

Sin pecar de alarmismos, que bastantes tenemos, el reto tecnológico gestado en el mundo posindustrial ojalá nos ayude a unir esfuerzos y acercar grupos sociales hoy por hoy dispersos y enfrentados.

En la concertación social en pro de una economía para la paz están más directamente implicados el gobierno, el sector empresarial y los gremios laborales, en mayor o menor conexión con los respectivos partidos políticos. Las preocupaciones por lograr crecimiento con equidistribución o de aliviar los costos sociales del modelo neoliberal tienden a concentrar el proceso de la reconstrucción en un marco preferentemente nacional y político. Añadido a estos dialogantes, el desafío tecnológico introdu ce como nuevo actor clave de la reconstrucción a ese conjunto difuminado de instituciones de investigación, ciencia y tecnología, comprendiendo a la Universidad y su función de hacer ciencia. Estas circunstancias de posguerra nacional requieren injertar la tecnología en el proceso de paz, y en consecuencia las instituciones de ciencia y tecnología deben integrarse en todo el proceso de la reconstrucción económica.

Estas consideraciones no agregan nada nuevo al hecho de integrarnos en la corriente mundial de la economía de mercado, aunque sí subrayan un elemento cualitativo. Cuando hablamos de las leyes de la oferta y demanda, pensamos espontáneamente en mercados y cantidades mayores o menores que normalizan el nivel de precios. No podemos olvidar que el gran valor de uso, el determinante de los precios competitivos, lo genera el progreso tecnológico, es decir, la ciencia y la investigación aplicada a las innovaciones productivas. En este aspecto nos hallamos seriamente rezagados el gobierno, el sector privado, las gremiales laborales y la universidad en su conjunto.

Este es un dato objetivo en el doble significado del desafío del progreso tecnológico; no se trata simplemente de hacer las mismas cosas con nuevos métodos modernizados, sino también de producir nuevos bienes y servicios, de integrar en nuestro proceso económico nuevos encadenamientos sectoriales, descuidados en el pasado y necesarios en el presente para conjugar el desarrollo hacia afuera con el impostergable de- 
sarrollo hacia adentro. Esta aplicación de la tecnología viene a reforzar la reintegración centroamericana y a dar una respuesta a la creación de mayor nivel de empleo en el interior nacional. Este enfoque cuantitativo y cualitativo de la tecnología ojalá sirva a unir grupos y fuerzas que la historia y las teorías han tratado de disociar.

En virtud de las cláusulas de un modelo neoliberal y de una sumatoria de accidentes históricos de la pasada década, se tiende a diluir la presencia y la función gerencial del Estado dentro del quehacer económico. Las acusaciones de ineficiencia, despilfarro, nepotismo político y corrupción han servido para justificar una conclusión predeterminada: el sector 廿 privado será el eje central de la nueva economía. Sin embargo, por sumatoria también de hechos históricos de las tres últimas décadas, el sector privado se ha revelado relativamente improductivo y no tan capacitado para aguantar la competencia tecnológica:

Ya se ha apuntado que la apertura gradual de los mercados - base de la reconversión industrial - debe ser acompañada por nuevas fuentes de innovación en materia técnica, gestión, mercadeo, infraestructura e información comercial. Sin ellas, la apertura puede provocar el desmantelamiento de la planta industrial más que su perfeccionamiento y competitividad. Superado el aislamiento de la economía y reducido el proteccionismo, las empresas deberán preservar y ganar posiciones con el auxilio de estas nuevas herramientas. De lo contrario, los empresarios manifestarán otras preferencias como la discontinuidad de sus inversiones, su traslado a sectores especulativos, y/o el desempeño de papel de importadores en franco entendimiento con empresas transnacionales. A la racionalidad de los empresarios debe oponerse la racionalidad de la gestión gubernamental. En otras palabras, el Estado debe redefinir sus funciones y sus procedimientos conforme a las exigencias de la nueva cultura económica. De momento el sector productivo salvadoreño presenta los rasgos característicos de un esquema sustentado en la protección, en regulaciones excesivas, en la falta de criterios de calidad, y en un desarrollo manufacturero tecnológicamente poco innovador. Y ya empieza a transitar a otro, más abierto y competitivo, sin contar con los auxilios necesarios para un tránsito atinado. Es aspiración básica de este programa ofrecer criterios, procedimientos, orientaciones y recursos dirigidos a facilitar la transformación estructural de la economía (Hodara, 1992, pp. 5-6).

No hay lugar a repetir las relaciones de compadrazgo y proteccionismo de las décadas 1950 y 1960, que el $\mathrm{Dr}$. J. Hodara resume atinadamente:

Se pretendía entonces gestar una planta industrial sin afectar sustancialmente al sector agrario; tampoco se establecieron bases tecnológicamente autónomas. Por el contrario, el Estado jefaturó este crecimiento a través de una vasta red proteccionista que le permitía al empresario sobrevivir y obtener utilidades, a pesar de que jamás se expuso a la competencia internacional. En este contexto, las innovaciones parecian prescindibles. $Y$ en la medida en que se precisaban, firmas extranjeras las suministraban. La formación del Mercado Común estimuló 
sin duda al sector manufacturero nacional. Al menos le facilitó una demanda más amplia en un mercado relativamente conocido. Sin embargo, los estímulos no fueron tan intensos como para gestar una infraestructura científico-técnica adecuada, incluyendo redes y vínculos entre los actores del desarrollo industrial (lbid., p. 3).

Tomando en cuenta la adversa coyuntura internacional, la destrucción del capital nacional en el periodo de guerra, la fuga de capital privado y la obsolescencia consecuente del equipo productivo, el propio sector privado demanda una marcha gradual hacia el mercado internacional. En otras palabras, el sector privado debe hacer su autoevaluación y moderar su complejo de superioridad relativa.

Si hablamos de ciencia y tecnología, también la Universidad salvadorefia necesita hacer la más sincera autocritica y aceptar su culpabilidad en este rezago técnico generalizado. Luego del desmantelamiento de la UES y la proliferación descontrolada de universidades privadas, la calidad universitaria es función inversa de la cantidad de instituciones oficialmente aprobadas. La competencia académica se degrada, los títulos profesionales pierden su valor de uso y su credibilidad científica.

La Universidad, conjunto integrado por unas cuarenta instituciones, ha fallado en su función de hacer ciencia y "con-ciencia" de la realidad, innovando nuevas sendas del desarrollo. Los borradores engavetados de la Ley de Educación Superior ni han frenado la dispersión de la ensefianza comercial, ni menos han motivado la investigación científica. Carecemos de una inversión universitaria con profesionales integralmente dedicados a la investigación-docencia, dotados de la infraestructura física y académica minimamente requerida para sus funciones. La triste consecuencia es el recurso a las técnicas y a los técnicos importados a precio de divisa-fuerte. Otro aspecto más de nuestra debilidad frente al mercado internacional.

Queda por decir dos palabras de ese cuarto grupo dialogante, que no es gobierno, no es sector privado, ni alcanza a llegar a la universidad; es simplemente la mayoría de la clase trabajadora. Sin más medios de producción que sus propias cualidades, son reconocidos nacional e internacionalmente por su laboriosidad, creatividad y aguante en el trabajo. Algo dicen a su favor los $\$ 700$ millones de remesas de emigrantes, que sostienen al actual modelo, así como las organizaciones de comunidades productivas localizadas en un entomo geográfico adverso. Sin embargo, a este sector laborioso y creativo no se le ha brindado la oportunidad de su educación personal y autodesarrollo técnico. Por lo menos, el Plan de Reconstrucción Nacional recuerda la necesidad de la formación del capital humano, que es el primer capital. Esto plantea la pregunta: 
tecnología ¿para quién y a servicio de quién?

Si la citada afirmación, "los países que no se adaptan a las nuevas modalidades verán comprometida su viabilidad como entidades nacionales y económicas", enuncia una premisa cierta, el desafío tecnológico debe unir a los cuatro grupos hasta aquí mencionados, que en el pasado $y$ en el presente han mantenido una coexistencia distanciada y excluyente. La Universidad, como conjunto, ha dado escasos aportes a la transformación de la realidad nacional. El Estado y el sector privado, que en la década pasada se miraban como competidores excluyentes, en la presente década coinciden en afirmar que el mejor gobierno es el que menos gobierna. Al proclamar las ventajas comparativas del mercado neoliberal y concentrarnos en un sector privado poco competitivo, corremos el riesgo de la desnacionalización económica. Contamos sí con una laboriosa mano de obra, cuyo gran aporte nacional va más en la línea de incrementar su productividad que en buscar las ventajas comparativas por la reducción de sus salarios mínimos.

Lo que buscan estas reflexiones es unir to hasta aqui disperso. Quizás el Foro de Concertación Económica-Social es visto como una palestra donde las partes dialogantes buscan sus respectivas ventajas económicas. Pero, a mediano plazo, ni éste ni otro modelo socializante tendrán éxito si no avanzamos a la nacionalización económica gracias a la renovación tecnológica apropiada. El hecho de que hablemos de sector formal (¿moderno?) e informal, de que el Plan de Reconstrucción integre un conjunto de proyectos sencillos de infraestructura física y social, de que se enfatice tanto el desarrollo hacia dentro como el desarrollo hacia fuera, significa que la tecnologia, en singular, se abre en un abanico de variadas tecnologías, las unas más intensas en capital, las otras más intensas en trabajo.

Tendremos unas tecnologías más bien importadas, pero se requiere crear la tecnología apropiada a nuestra dotación de recursos físicos y humanos. La modernización debe afectar tanto al equipo técnico como a la optimización de nuestros recursos físicos y sobre todo al valioso capital humano. En este orden, una tecnología sustentable será también aquella que nos lleve a la formación de cadenas internas por transformaciones sucesivas (río-abajo) de productos hoy exportados en sus estadios primitivos o no utilizados (papel de la agroindustria), o por transformaciones sucesivas (rio-arriba) de bienes finales o intermedios importados. Hay que crear aquella tecnologia que nos asegure un mayor nivel de empleo por razones sociales como tecnológicas. La tecnología renueva al hombre y el hombre renueva la tecnología. De ahi la imprescindible necesidad del desarrollo hacia dentro. 
Es posible evaluar y relanzar el progreso tecnológico tanto desde una análisis de nuestra capacidad interna como desde el desafío que nos lanza el comercio internacional. Sin duda poseemos unos inventarios tecnológicos no aprovechados. Los departamentos de ingeniería, desde la agronómica hasta la más sofisticada electrónica, han generado investigaciones concretas aplicadas pero inutilizadas mientras duermen en el limbo de las bibliotecas. Ha habido symposiums de tecnología apropiada, pero muchos inventos no se han convertido en innovaciones. Los departamentos de administración de empresas también han dejado escritas valiosas recomendaciones para la empresa nacional y a su vez la empresa nacional, a través de encuestas-entrevistas, ha dado pautas a la universidad para formar a los adecuados profesionales de la empresa moderna, readecuando para ello los planes y programas de estudio. Los departamentos de economía y otras instituciones de investigación se han esforzado por hacer una crítica constructiva y reformulaciones de modelos alternativos...

Son estos y otros más los inventarios inactivos que el Programa de Ciencia y Tecnologia pretende activar por la integración efectiva de todos los agentes y beneficiarios del progreso técnico. Si ha habido un diálogo para hacer la paz, nos queda por delante el diálogo para hacer tecnología aplicada. Entre otros fines, esto puede rescatar de su aislamiento a la Universidad salvadoreña e integrarla en la reconstrucción nacional, integrándose a su vez en los proyectos del Estado y en los programas de modernización del sector empresarial.

Otra forma de evaluar comparativamente nuestra posición tecnológica es hacer un análisis, aunque sea superficial, de nuestra balanza comercial, que de manera bastante cercana mide nuestro grado de competitividad frente a los mercados regionales y extrarregionales. No hay duda de que nuestra posición tecnológica y su evolución se refleja en la estructura de nuestras exportaciones-importaciones. Este somero análisis mide nuestros avances y nuestras lagunas y puede ayudar a trazar sendas nuevas en el desarrollo tecnológico.

\section{La tecnología en nuestra balanza comercial.}

Hay que reconocer que algunos éxitos contables del actual proceso económico no se deben tanto a un potencial interno y autosostenible cuanto a inyecciones externas, ayudas, donaciones, remesas de emigrantes que sostienen nuestro tipo de cambio en cierta estabilidad. Si nuestra balanza de pagos llega a presentar temporalmente signos positivos, nuestra balanza comercial, con Centroamérica y el resto del mundo, sigue 
aguantando un déficit creciente, que sólo gracias a transferencias unilaterales privadas y oficiales alcanza, un año si y otro no, un superávit en la cuenta corriente.

No se trata de ponderar aquí el efecto que el "índice del tipo de cambio real" (ITCER) pueda ejercer sobre el volumen y valor de las exportaciones e importaciones, sobre los bienes transables y no transables 19891991. Un análisis más acucioso puede leerse en los informes trimestrales de coyuntura publicados por FUSADES (Véase FUSADES, 1991, pp. 37-41). De sobra es conocido que la tendencia decreciente de los precios del café, iniciada en la década de 1980, se profundiza a partir de 1989 , afectando el déficit en la balanza comercial; en consecuencia, podemos observar que el incrementos de las exportaciones no tradicionales supera en 1990 el valor de las exportaciones de café, y supera en 1991 el valor de todas las exportaciones tradicionales.

El sensible incremento de las exportaciones no tradicionales junto con el déficit comercial con Centroamérica y el resto del mundo (Cuadro 1), indican dos áreas de urgente renovación tecnológica aplicada, en orden a incrementar las primeras (exportaciones no-tradicionales) y reducir las segundas (importaciones) en su componente de bienes de consumo. Una primera área geográfica donde los avances tecnológicos pueden mejorar nuestra posición competitiva y donde las exportaciones no tradicionales presentan un ritmo creciente es el Mercado Común Centroamericano. No se trata de transformar nuestra balanza comercial deficitaria en balanza comercial positiva frente a cada uno de los países del istmo, porque si todos ellos se trasforman en nuestros deudores comerciales pudieran enfriarse las renovadas pláticas integracionistas.

Más interesante sería que, en la medida de lo posible y por integración de nuestras matrices intersectoriales, se pudiera lograr una mejor especialización de la producción y un sólido crecimiento conjunto gracias a la transferencia de mercancias, de inversión financiera y de capital humano que diera lugar a un mejor equilibrio regional hombre/tierra. La razón de aplicar los avances tecnológicos a las exportaciones no tradicionales es doble, de acuerdo a la lectura que podemos hacer de los cuadros 2 y 3 , que muestran la composición de dichas exportaciones.

Los cuadros 2 y 3 nos muestran que las mismas exportaciones no tradicionales tienen como destino países de dentro y fuera del istmo centroamericano, aunque no en la misma proporción; no estamos capacitados para colocar fuera de Centroamérica tanta maquinaria, material eléctrico o manufacturas metálicas como podemos hacerlo al interior del istmo. 'Se diría que podemos penetrar el mercado internacional con pro- 
Cuadro 1

El Salvador: Exportaclones y Balanza Comercial

(Miles de dólares y miles de kilogramos)

\begin{tabular}{|l|r|r|r|r|}
\hline Concepto & 1991: Valor & Volumen & $1990:$ Valor & Volumen \\
\hline I. Exportaciones (FOB) & $\mathbf{5 8 7 . 9 9 9}$ & $\mathbf{4 6 4 . 3 8 3}$ & $\mathbf{5 8 2 . 2 4 3}$ & $\mathbf{4 2 3 . 8 6 5}$ \\
A. Tradiclonales & 272.099 & $\mathbf{2 1 1 . 2 9 4}$ & 296.251 & $\mathbf{1 9 7 . 6 0 1}$ \\
1. Caf́́ & 219.530 & 127.467 & 260.283 & 148.661 \\
2. Algodón & 751 & 383 & 1.307 & 940 \\
3. Azúcar & 31.953 & 80.269 & 20.281 & 44.913 \\
4. Camarón & 19.865 & 3.175 & 14.380 & 3.087 \\
B. No tradiclonales & 315.900 & 253.089 & 285.992 & 226.264 \\
1. Centroamérica & 193.732 & 128.094 & 173.025 & 96.252 \\
2. Fuera de Centroamérica & 1.164 .476 & 2.120 .156 & 1.054 .164 & 1.988 .764 \\
III. Balanza Comerclal & 817.967 & 2.036 .884 & 680.234 & 1.936 .023 \\
\hline
\end{tabular}

Fuente: BCR. Sección Balanza de Pagos; Marzo - 1992.

ductos del reino vegetal y textiles, además del calzado, si no hubiera restricciones a este artículo. Esto significa que los avances tecnológicos aplicados a estos productos y el aprendizaje del mercado ayudarán a penetrar cuantitativa y cualitativamente en el mercado internacional.

En segundo lugar, este listado de exportaciones no tradicionales son al mismo tiempo productos reclamados en el mercado interno. Los avances tecnológicos, traducidos en mejor calidad y menores costos unitarios, expandirían tanto el mercado intemo y extemo de las empresas. Por ello, todas las medidas que se tomen en pro de una mayor equidistribución de los ingresos o con vistas a la generación de nuevos empleos servirian a reactivar el mercado y la capacidad instalada de las empresas. Adicionalmente, un estadio superior a recorrer por las exportaciones no tradicionales es ir sustituyendo productos exportados en su fase primitiva por productos internamente manufacturados por la agroindustria. Se trata de las cadenas productivas "río-abajo", que se comentan más adelante (Véase Donis, 1988).

Como nuestra primera área de integración geográfica y primer estadio para someter a prueba nuestra capacidad competitiva es el istmo centroamericano, el cuadro 4 nos muestra la posición comercial con cada uno de estos paises. 
Cuadro 2

El Salvador: Exportaciones de productos

no tradicionales a Centroamerica

(Miles de dólares y miles de Kgrs.)

\begin{tabular}{|c|c|c|c|c|}
\hline Sección NAUCA & 1991 Valor & Volumen & 1990 Valor & Volumen \\
\hline $\begin{array}{l}\text { 1. Animales vivos y } \\
\text { productos del reino } \\
\text { animal }\end{array}$ & 2.482 & 1.429 & 1.961 & 883 \\
\hline $\begin{array}{l}\text { 2. Productos } \\
\text { del reino vegetal } \\
\text { (café soluble) }\end{array}$ & $\begin{array}{l}1.182 \\
(159)\end{array}$ & $\begin{array}{r}2.403 \\
(82)\end{array}$ & $\begin{array}{r}1.212 \\
(39)\end{array}$ & $\begin{array}{r}3.207 \\
(4)\end{array}$ \\
\hline $\begin{array}{l}\text { 3. Productos de las } \\
\text { Industrias Alimenticias, } \\
\text { bebidas-tabaco }\end{array}$ & 23.609 & 25.792 & 12.455 & 11.658 \\
\hline 4. Productos minerales & 2.549 & 17.296 & 4.110 & 10.583 \\
\hline $\begin{array}{l}\text { 5. Productos Industrias } \\
\text { Químicas }\end{array}$ & 42.841 & 26.683 & 36.938 & 18.625 \\
\hline $\begin{array}{l}\text { 6. Productos-Artículos } \\
\text { Papel-Cartón }\end{array}$ & 30.023 & 21.730 & 28.940 & 20.728 \\
\hline $\begin{array}{l}\text { 7. Materias textiles } \\
\text { y manufactura }\end{array}$ & 32.852 & 6.614 & 27.142 & 5.001 \\
\hline $\begin{array}{l}\text { 8. Calzados y artículos } \\
\text { análogos }\end{array}$ & 7.748 & 1.627 & 8.464 & 1.690 \\
\hline $\begin{array}{l}\text { 9. Metales comunes y } \\
\text { manufacturas }\end{array}$ & 22.954 & 10.404 & 24.980 & 11.700 \\
\hline $\begin{array}{l}\text { 10. Máquinas-aparatos } \\
\text { Materiales eléctricos }\end{array}$ & 10.884 & 2.698 & 12.181 & 2.995 \\
\hline 11. Otras secciones & 16.608 & 11.418 & 14.640 & 9.182 \\
\hline TOTAL & 193.732 & 128.094 & 173.025 & 96.252 \\
\hline
\end{tabular}




\section{Cuadro 3}

El Salvador: Exportaciones de productos no tradicionales fuera de Centroamerica

(Miles de dólares y miles de Kgrs.)

\begin{tabular}{|c|c|c|c|c|}
\hline Sección NAUCA & (1991)Valor & Volumen & (1990)Valor & Volumen \\
\hline $\begin{array}{l}\text { 1. Animales vivos y } \\
\text { productos del reino } \\
\text { animal }\end{array}$ & 5.280 & 3.357 & 2.257 & 1.736 \\
\hline $\begin{array}{l}\text { 2. Productos del reino } \\
\text { vegetal } \\
\text { (café soluble) }\end{array}$ & $\begin{array}{l}29.939: \\
(2.408)\end{array}$ & $\begin{array}{r}39.402 \\
(1.361)\end{array}$ & $\begin{array}{l}24.159 \\
(3.729)\end{array}$ & $\begin{array}{r}27.303 \\
(781)\end{array}$ \\
\hline $\begin{array}{l}\text { 3. Productos de las } \\
\text { Industrias Alimenticias, } \\
\text { bebidas-tabaco }\end{array}$ & 5.068 & 50.718 & 4.688 & 30.752 \\
\hline 4. Productos minerales & 1.494 & 12.638 & 4.934 & 52.149 \\
\hline $\begin{array}{l}\text { 5. Productos Industrias } \\
\text { Químicas }\end{array}$ & $8.956^{3}$ & 1.417 & 8.364 & 1.096 \\
\hline $\begin{array}{l}\text { 6. Productos-Artículos } \\
\text { Papel-Cartón }\end{array}$ & 5.161 & 2.187 & 4.963 & 2.073 \\
\hline $\begin{array}{l}\text { 7. Materias textiles } \\
\text { y manufactura }\end{array}$ & 48.309 & 10.556 & 40.7671 & 8.564 \\
\hline 8. Calzados y artículos & 5.747 & 363 & 6.782 & 494 \\
\hline $\begin{array}{l}\text { 9. Metales comunes y } \\
\text { manufacturas }\end{array}$ & 4.871 & 1.725 & 4.346 & 1.378 \\
\hline $\begin{array}{l}\text { 10. Máquinas-aparatos } \\
\text { Materiales eléctricos }\end{array}$ & 1.634 & 584 & 2.537 & 206 \\
\hline 11. Otras secciones & 5.709 & 2.048 & 9.170 & 4.257 \\
\hline TOTAL & 122.168 & 124.995 & 112.967 & 130.012 \\
\hline
\end{tabular}

Fuente: BCR. Sección-Balanza de Pagos. Marzo - 1992.

La balanza comercial de El Salvador con el conjunto de países del istmo centroamericano mantiene su posición deficitaria, situación presente a lo largo de la década de 1980 dentro de oscilaciones explicables por la situación económica y las evoluciones de los tipos de cambio. Expresado en dólares, el déficit comercial venía decreciendo de 1987 a 1990 para elevarse en 1991. Un movimiento en sentido contrario se observa en el intercambio comercial con Panamá, donde los saldos positi- 
vos se convierten en negativos sobre todo cuando se incluye el intercambio con la Zona del Canal. En relación a Costa Rica, nuestra balanza comercial, normalmente deficitaria, logra un notorio superávit en los años 1990-1991. Bastante similar es nuestra relación con Honduras, mientras que la balanza comercial con Nicaragua, normalmente positiva, resiente un déficit en 1989-1990 y vuelve a contabilizar números positivos en 1991. Esta posición deficitaria de nuestra balanza comercial afecta nuestra tradicional deuda comercial con Guatemala.

\section{Cuadro 4 \\ Comerccio de El Salvador con Centroamerica Y Panamá (Miles de dólares y miles de Krgs)}

\begin{tabular}{|c|c|c|c|c|}
\hline Concepto & $\begin{array}{l}1991 \\
\text { Valor }\end{array}$ & $\begin{array}{c}1991 \\
\text { Volumen }\end{array}$ & $\begin{array}{l}1990 \\
\text { Valor }\end{array}$ & $\begin{array}{c}1990 \\
\text { Volumen }\end{array}$ \\
\hline I. EXPORTACIONES & 203.669 & 141.849 & 181.908 & 124.214 \\
\hline A. Mercado Común Cen & 193.732 & 128.094 & 173.025 & 96.252 \\
\hline - Guatemala & 107.600 & 76.363 & 100.622 & 61.457 \\
\hline - Honduras & 21.523 & 16.116 & 17.447 & 9.231 \\
\hline - Nicaragua & 20.682 & 15.778 & 7.133 & 6.009 \\
\hline - Costa Rica & 43.927 & 19.837 & 47.823 & 19.555 \\
\hline B. Panamá & & & & \\
\hline (incluye Zona-Canal) & $\mathbf{9 . 9 3 7}$ & 13.755 & 8.883 & 27.962 \\
\hline II. IMPORTACIONES & 286.902 & 392.169 & 245.917 & 383.611 \\
\hline A. Mercado Común Centroamer. & 241.490 & 381.111 & 280.313 & 371.124 \\
\hline - Guatemala & 163.893 & 262.227 & 145.417 & 239.469 \\
\hline - Honduras & 18.661 & 48.874 & 15.708 & 66.612 \\
\hline - Nicaragua & 17.508 & 41.135 & 10.261 & 37.987 \\
\hline - Costa Rica & 41.428 & 28.875 & 36.927 & 27.056 \\
\hline B. Panamá & & & & \\
\hline (incluye Zona-Canal) & 45.412 & 11.058 & 37.604 & 12.487 \\
\hline III. SALDO (I-II) & 83.233 & 250.320 & 64.009 & 259.397 \\
\hline A. Mercado Común Centroamer. & 47.758 & 253.017 & 35.288 & 274.872 \\
\hline - Guatemala & 56.293 & 185.864 & 44.795 & 178.012 \\
\hline - Honduras & 2.862 & 32.758 & 1.739 & 57.381 \\
\hline - Nicaragua & 3.174 & 25.357 & 3.128 & 31.978 \\
\hline - Costa Rica & 2.499 & 9.038 & 10.896 & 7.501 \\
\hline B. Panamá & & & & \\
\hline (incluye Zona-Canal) & 35.475 & 2.697 & 28.721 & 15.475 \\
\hline
\end{tabular}

Fuente: BCR. Sección de Balanza de Pagos. Marzo de 1992. 
Se trata de una aproximación superficial para iluminar el campo de acción posible a nuestra renovación tecnológica. Como se indica en FUSADES (1991, p. 101), las encuestas pasadas entre empresas exportadoras revelan un conjunto de elementos que traban la fluidez del comercio regional. En orden de importancia se citan el tipo de cambio (sobrevaluado relativamente), las trabas aduanales, dificultades de transporte, los impuestos (aranceles) y otros. Si con los acuerdos bilaterales de libre comercio (EI Salvador-Guatemala, El Salvador-Honduras...) se llega a una unificación de aranceles, a una simplificación de trámites aduaneros y del sistema de pagos compensatorios, en dirección de un verdadero mercado común, junto con el indice de tipo de cambio efectivo real (ITCER), serán las innovaciones tecnológicas las que tendrán un mayor efecto benéfico sobre la evolución de la balanza comercial.

FUSADES tiende a enfatizar el efecto catalizador del tipo de cambio real al poner el eje del crecimiento en el impulso a las exportaciones:

Por tanto es importante mantener una adecuada competitividad en el exterior por medio de un tipo de cambio realista. Esto permitirá además alcanzar un crecimiento económico sostenible liderado por los sectores transables de la economía (FUSADES, 1992a, p. 1).

Aparte de la postura teórica subyacente, entran aquí en juego las repercusiones más sensibles de las elasticidades de nuestras exportaciones-importaciones a las variaciones del tipo de cambio. Sea dicho de paso que siguen siendo muy cuestionadas las bases teóricas-analíticas y los resultados de los programas de ajuste del FMI, como lo ha esclarecido recientemente Lisandro Abrego sobre la base de numerosos autores e investigaciones. Sirva de muestra el siguiente párrafo referido a los posibles efectos de la devaluación:

¿Por qué los resultados son menos "exitosos" con relación a la inflación? Nuestra hipótesis es que, de cara a este objetivo, el programa del Fondo no es muy coherente internamente y que, como resultado de su reduccionismo en su explicación, parte de un diagnóstico muy pobre de las causas de la inflación, que se traduce en un también pobre diseño. En cuanto a la coherencia, políticas necesarias para corregir el equilibrio externo, como la devaluación, tienen a agravar la inflación, aun cuando otras, un mayor control del crédito, pudieran contribuir a disminuir ambos desequilibrios. En materia de inflación, por lo tanto, lo que los programas pueden hacer con la contracción del crédito pueden deshacerlo con la devaluación. En el estrecho marco teórico del Fondo, el resultado global depende de cuál de esos dos efectos predomina. Ahora bien, pareciera que cuando hay una tradición inflacionaria, las expectativas tienden a hacer que predomine el efecto de la devaluación, puesto que cuando un programa contiene medidas que aumentan el nivel de los precios y otras que pueden reducirlo es más probable que el público preste mayor atención a las primeras y no espere una menor inflación, y contribuya así a que sus expectativas se realicen... Resulta difícil 
establecer hasta qué punto los programas del Fondo, con su preocupación por el efecto precios relativos de la devaluación, toman en consideración en su meta de inflación, el impacto de la devaluación - aunque sería ingenuo pensar que ingenuamente lo ignoran-, impacto que se torna aún más importante cuando el fenómeno porta un fuerte componente inercial (Abrego, 1991, p. 598).

\section{Cuadro 5}

Clasificación económica de las importaciones enero-diciembre

(Miles de dólares y miles de Kgrs)

\begin{tabular}{|l|r|r|r|r|}
\hline \multicolumn{1}{|c|}{ Categoría } & \multicolumn{1}{c|}{$\begin{array}{r}1991 \\
\text { Valor }\end{array}$} & $\begin{array}{r}1991 \\
\text { Volumen }\end{array}$ & \multicolumn{1}{c|}{$\begin{array}{r}1990 \\
\text { Valor }\end{array}$} & \multicolumn{1}{c|}{$\begin{array}{c}1990 \\
\text { Volumen }\end{array}$} \\
\hline I. Bienes de Consumo & 372.730 & 460.198 & 398.843 & 709.831 \\
A. No Duraderos & 321.997 & 447.121 & 361.375 & 700.128 \\
B. Duraderos & 50.733 & 13.077 & 37.468 & 9.703 \\
II. Bienes Intermedios & 709.980 & 1.976 .143 & 629.111 & 1.595 .895 \\
A. Industria Manufacturera & 547.362 & 1.578 .796 & 486.393 & 1.212 .411 \\
(Petróleo) & $(126.755)$ & $(765.686)$ & $(121.834)$ & $(689.798)$ \\
B. Agropecuario & 67.738 & 279.468 & 57.996 & 275.228 \\
$\quad$ (Fertilizantes) & $(30.201)$ & $(257.902)$ & $(29.847)$ & $(255.508)$ \\
C. Construcción & 85.939 & 112.416 & 78.280 & 104.619 \\
D. Otros & 8.941 & 5.463 & 6.442 & 3.637 \\
III. Bienes de Capital & 323.256 & 64.926 & 234.523 & 54.162 \\
A. Industria Manufacturera & 89.221 & 11.107 & 71.083 & 10.668 \\
B. Transporte & 148.855 & 42.556 & 102.554 & 34.946 \\
C. Agropecuario & 11.063 & 4.735 & 8.929 & 4.253 \\
D. Construcción & 11.539 & 1.711 & 8.340 & 1.135 \\
E. Otros & 62.578 & 4.817 & 43.617 & 3.160 \\
\hline \multicolumn{1}{|c|}{ TOTAL } & 1.405 .966 & 2.501 .267 & 1.262 .477 & 2.359 .888 \\
\hline
\end{tabular}

Fuente: BCR. Sección Balanza de Pagos. Marzo de 1992.

Cuando nuestras importaciones tienen una elevada inelasticidad precio-demanda el efecto más inmediato de la devaluación se resiente en el mayor costo de los bienes importados, que afectarán al nivel de los precios internos. El mismo informe de FUSADES (1992a) sefiala que si el tipo de cambio sobrevaluado facilitó las importaciones de bienes de consumo, también alentó notoriamente las importaciones de bienes intermedios y sobre todo de bienes de capital indispensables para la reconversión industrial y la renovación tecnológica. Mientras que la política del tipo de cambio, como palanca principal, puede animar el flujo de las exportaciones, pero frenando o encareciendo el monto de las importaciones 
de bienes intermedios y de capital, la investigación científica y la tecnología aplicada reanimarían el desarrollo hacia adentro y hacia afuera de nuestra economia. Por lo tanto, el progreso tecnológico tiene un nuevo reto de cara a la estructura de nuestras importaciones.

Una lectura más detallada de la composición de nuestras importaciones (Cuadro 5), tal como se clasifican en la revista mensual del BCR, muestra la necesidad de mejorar el proceso de transformación manufacturera vía actualización tecnológica. Nuestra dotación de recursos productivos, materias primas y bienes intermedias son relativamente escasos por obra del hombre (ecosistema) y de la naturaleza. Llama la atención que en una economía agraria se mantenga relativamente elevado el porcentaje de importaciones de productos alimenticios básicos y otras materias primas propias del campo. Los gustos exógenos generados por las empresas transnacionales y el efecto imitación de las minorias relativamente pudientes explican en buena parte este género de importaciones.

Por su parte, la monoexportación tradicional ha relegado a áreas marginales estos productos básicos para el desarrollo interno, de suerte que nuestro I.P.C. está siempre condicionado y superado por el índice de precios de los alimentos. Siendo diciembre de 1978 la base $=100$, el Indice General de Precios al Consumidor es 862,43 (febrero - 1992), destacándose los alimentos con el índice 1.084,59, y entre ellos las frutas y vegetales con el indice 2.916,02. Grave costo social del desarrollo hacia afuera.

La urgencia de la actualización tecnológica en el proceso de transformación se aprecia en el creciente porcentaje de importaciones de materias primas e intermedias (productos minerales o materiales crudos, productos químicos, materias plásticas...), artículo manufacturados (amplia lista correspondiente a 18 ramas productivas), maquinaria y material de transporte. Las importaciones invaden los tres grandes sectores económicos, de manera que buscando abastecedores de abastecedores (ríoarriba) nos encontramos siempre con importaciones de equipo e insumos tal como lo muestra la sábana de coeficientes técnicos importados de la matriz 1978, tomando en cuenta que dicha estructura dependiente más bien se ha agravado a causa la guerra y del deterioro ecológico.

Difícilmente podemos evadir la sustitución de importaciones por otras importaciones y el desafío en curso es la cualificación de la transformación manufacturera agro o urbano industrial, tanto de los recursos propios como de los importados. Sobra decir que, dada la expansión demográfica y la dimensión de la pobreza, la investigación científica, los inventos e innovaciones deben imaginarse tanto para el desarrollo hacia adentro como para el desarrollo hacia afuera, porque no hay segundo sin primero. 
Cuadro 6

El Salvador: Exportaciones e importaciones por países enero-diciembre de 1991 (Miles de \$-USA)

\begin{tabular}{|c|c|c|c|c|c|c|c|}
\hline \multirow{2}{*}{\multicolumn{2}{|c|}{\begin{tabular}{|l} 
País o Región \\
\end{tabular}}} & \multicolumn{2}{|c|}{ EXPORTACIONES } & \multicolumn{2}{|c|}{ I MPORTACIONES } & \multicolumn{2}{|c|}{ SALDOS } \\
\hline & & Valor & $\%$ & Valor & $\%$ & Valor & $\%$ \\
\hline \multicolumn{2}{|c|}{ TOTAL } & 573.222 & 100.0 & 1.415 .443 & 100.0 & 842.221 & 100.0 \\
\hline I. & Países Industriales & 336.827 & 58.8 & 802.686 & 56.7 & 465.859 & 55.3 \\
\hline \multirow[t]{7}{*}{ A. } & Grupo de los siete & 323.687 & 56.5 & 758.285 & 53.6 & 434.598 & 51.6 \\
\hline & $\begin{array}{l}\text { - Estados Unidos } \\
\text { - Alemania }\end{array}$ & $\begin{array}{l}191.072 \\
105.422\end{array}$ & $\begin{array}{l}33.3 \\
18.4\end{array}$ & $\begin{array}{r}574.391 \\
59.911\end{array}$ & $\begin{array}{r}40.6 \\
4.2\end{array}$ & $\begin{array}{r}383.319 \\
45.511\end{array}$ & $\begin{array}{r}45.5 \\
5.4\end{array}$ \\
\hline & - Japón & 15.597 & 2.7 & 68.268 & 4.8 & 52.671 & 6.3 \\
\hline & - Francia & 1.763 & 0.3 & 13.412 & 0.9 & 11.649 & 1.4 \\
\hline & - Reino Unido & 1.577 & 0.3 & 20.595 & 1.5 & 19.018 & 2.3 \\
\hline & - Canadá & 5.241 & 0.9 & 13.301 & 0.9 & 8.060 & 1.0 \\
\hline & -1 & & 0.5 & 8.407 & 0.6 & 5.392 & 0.6 \\
\hline \multirow[t]{5}{*}{ B. } & Otros & 13.140 & 2.3 & 44.401 & 3.1 & 31.261 & 3.7 \\
\hline & - Españ & 2.66 & 0.5 & & 0.8 & & 1.0 \\
\hline & - Bélgica-Luxemburgo & 4.137 & 0.7 & 11.998 & 0.8 & 7.861 & 0.9 \\
\hline & - Hola & 5.289 & 0.9 & 18.529 & 1.3 & 13.240 & 1.6 \\
\hline & - Dina & 1.053 & 0.2 & 3.154 & 0.2 & 2.101 & 0.2 \\
\hline II. & Países en Desarrollo & 17.853 & 38.0 & 542.324 & 38.3 & 324.471 & 38.5 \\
\hline \multirow[t]{5}{*}{ A. } & Centroamérica & 193.732 & 33.8 & 241.490 & 17.1 & 47.758 & 5.7 \\
\hline & — Guatemala & 107.600 & 18. & & 11.6 & & 6.7 \\
\hline & - Costa Rica & 43.927 & 7.7 & 41. & 2.9 & 2.499 & 0.3 \\
\hline & - Nicaragua & 20.682 & 3.6 & 18.6 & 1.3 & 2.021 & 0.2 \\
\hline & - Honduras & & 3.8 & 17.508 & 1.2 & 4.015 & 0.5 \\
\hline \multirow[t]{9}{*}{ B. } & OTROS & 24.121 & 4.2 & 300.834 & 21.3 & 276.713 & 32.9 \\
\hline & (y Zona Canal) & 9.937 & 1.7 & 45.412 & 3.2 & 35.475 & 4.2 \\
\hline & - Argentina & 1.196 & 0.2 & 10.113 & 0.7 & 8.917 & 1.1 \\
\hline & - Brasil & 0 & 0.0 & 29.036 & 2.1 & 29.036 & 3.4 \\
\hline & - Chile & 555 & 0.1 & 6.265 & 0.4 & 5.710 & 0.7 \\
\hline & - México & 8.109 & 1.4 & 137.065 & 9.7 & 128.956 & 15.3 \\
\hline & - Venezuela & 184 & 0.0 & 57.641 & 4.1 & 57.457 & 6.8 \\
\hline & - Belice & 4.138 & 0.7 & 36 & 0.0 & 4.102 & 0.5 \\
\hline & - Taiwan & 2 & 0.0 & 15.266 & 1.1 & 15.264 & 1.8 \\
\hline III. & Demás Países & 18.542 & 3.2 & 70.433 & 5.0 & 51.891 & 6.2 \\
\hline
\end{tabular}

Fuente: BCR. Sección de Balanza de Pagos. Marzo de 1992.

A modo de escenario donde representan su papel nuestras exportaciones e importaciones, penetrando y siendo penetradas por el mercado mundial, el cuadro 6 ofrece una fotografía de nuestra balanza comercial con los paises en desarrollo para 1991. 
En la revista del BCR puede apreciarse la evolución de anos anteriores. Los valores porcentuales, así como los signos positivos y negativos, nos sitúan en el área geográfica y posición de la balanza comercial. Esta fotografía del último ejercicio en curso nos ubica en el mercado mundial que penetramos y que nos penetra y que, en expresión del Dr. J.Hodara, compromete nuestra viabilidad como entidades nacionales y económicas. Conjugando la estructura de nuestras exportaciones-importaciones, su destino y origen, y tomando en cuenta que en todas las regiones aquí agrupadas nuestra posición es sensiblemente deficitaria, no puede menos de tomarse muy en serio el desafío tecnológico. Es cuestión de supervivencia, y por ello el citado Programa de Ciencia y Tecnología requiere la integración de los esfuerzos orientadores del gobierno y sus Instituciones Públicas, el aporte decidido del sector empresarial, entendiendo por tal las nuevas relaciones de coexistencia y concertación del capital y del trabajo, junto con la creatividad e innovaciones científicas que las universidades y sus departamentos como otras instituciones de investigación aporten para generar tecnología apropiada a nuestra estructuración económica. Las exigencias tecnológicas se requieren tanto para consolidar nuestro desarrollo hacia adentro como el desarrollo hacia afuera, so pena de que una vez más la tecnología beneficie sólo al capital y en nada o en poco al trabajo. Nuestro recurso más importante es el capital humano y él es el hacedor principal de tecnología, como nos lo demuestra una mirada a los modos y formas de producción de los países desarrollados.

\section{Los coeficientes de interdependencia y dinamización económica}

Albert Hirschman (1964), en su tratado sobre estrategia del desarrollo económico, bajo el título de "un ejercicio mental", utiliza el análisis econométrico de H.B.Chenery y T. Watanabe: "Comparaciones internacionales de la estructura de producción". En la década de 1960 existía la preocupación por dinamizar el crecimiento de los países en vias de desarrollo. Las transferencias de tecnología no se podian hacer en el vacio, sino sobre determinadas estructuras de producción. W. Leontief había dicho que las matrices intersectoriales ofrecen sendas para el desarrollo; los paises pobres con frecuencia son pobres, no por carecer de recursos, sino por desconocer la manera de optimizar sus recursos. En consecuencia, era necesario analizar cómo los países industrializados lograban dinamizar sus economias. No se trataba de querer hacer lo mismo que ellos hacian, sino de trazar unas sendas para el desarrollo. Como nuestra balanza comercial nos integra en ese mundo industrial y hacia allá nos lleva el modelo de turno, podemos ilustrarnos con este ejercicio mental y econométrico. 
Chenery-Watanabe analizan el grado de interdependencia-dinamización de las diversas ramas productivas, calculando los valores promedios en tres paises (Italia, Japón y EUA) de lo que ellos llaman las relaciones sectoriales rio-arriba y río-abajo del proceso productivo. Puesto que el flujo económico arranca de la naturaleza y llega al mercado final a través de una secuencia encadenada de transformaciones, cada rama o sector productivo guarda una relación de dependencia (río-arriba) con los sectores que le ofrecen sus insumos, y una relación (río-abajo) con los sectores a quienes les suministra sus productos. Es posible clasificar a cada una de las ramas de acuerdo a su capacidad de dinamizar a sus sectores abastecedores por sus compras de insumos, así como de dinamizar a los sectores demandantes por su oferta de productos a transformar. Sumando ambos efectos se adjudican los coeficientes de capacidad dinamizante a cada rama productiva.

Ellos dividen las ramas productivas en dos categorias: industrias manufactureras y producción primaria, subdividiendo a ambos grupos en sectores intermedios y finales. Así, todo el proceso de transformación se realiza en cuatro grupos de empresas. Una vez clasificadas, el coeficiente de interdependencia río-arriba para cada rama se define y calcula como "la relación entre compras intersectoriales y la producción total". En otras palabras, el coeficiente de interdependencia rio-arriba aparece en la columna correspondiente de la matriz insumo-producto. El coeficiente de interdependencia río-abajo se define y calcula como "la relación entre las ventas intersectoriales (demanda intermedia) y la demanda total", quedando reflejado en la fila correspondiente de la misma matriz. Sumando ambos efectos tenemos una medida del potencial dinamizante de cada rama productiva.

Es normal que los mismos países industrializados, preocupados por su crecimiento económico y el reto del bloque socialista, tomaran muy en serio estos análisis econométricos. Más que normal, es necesario que nuestras economías preocupadas por el crecimiento y a sabiendas de que carecemos de esa malla intersectorial compleja, analicemos las vías posibles de rellenar algunas de las lagunas de nuestra estructura trunca y dependiente. Con este fin se presenta el cuadro 7.

Es claro que nuestra economía no contiene una malla intersectorial con todos estos sectores en cadena,desde la extracción hasta el producto final. El problema es que nos desprendemos de productos primarios - vía exportaciones- cuando pudieran dinamizar río-abajo al resto de sectores, asi como damos los toques finales o utilizamos equipos importados ue han dinamizado río-arriba economías externas. Sin embargo, como nos interesa aplicar la renovación tecnológica a la creación de sectores 
Cuadro 7

Valor promedio de los coeficlentes de Interdependencla de los sectores económicos (Italia, Japón y EE.UU)

\begin{tabular}{|c|c|c|}
\hline $\begin{array}{l}\text { Clasificación de los } \\
\text { sectores económicos }\end{array}$ & $\begin{array}{l}\text { Coeficiente } \\
\text { río-arriba }\end{array}$ & $\begin{array}{l}\text { Coeficiente } \\
\text { río abajo }\end{array}$ \\
\hline \multicolumn{3}{|c|}{ Industrias manufactureras intermedias (1) } \\
\hline Siderurgia & 66 & 78 \\
\hline Metales no ferrosos & 61 & 81 \\
\hline - Papel y sus productos & 57 & 78 \\
\hline Productos del petróleo & 65 & 68 \\
\hline Productos del carbón & 63 & 67 \\
\hline Productos químicos & 60 & 69 \\
\hline Textiles & 67 & 57 \\
\hline Articulos de caucho & 51 & 48 \\
\hline Imprenta y ediciones & 49 & 46 \\
\hline \multicolumn{3}{|l|}{ Industrias Manufactureras finales (2) } \\
\hline Molinería & 89 & 42 \\
\hline Cuero y artículos de cuero & 66 & 37 \\
\hline Madera y artículos de madera & 61 & 38 \\
\hline Vestido & 69 & 12 \\
\hline Equipo de transporte & 60 & 20 \\
\hline Maquinaria & 51 & 28 \\
\hline Productos minerales no metálicos & 47 & 30 \\
\hline Industrias alimenticias & 61 & 15 \\
\hline Construcción de navlos & 58 & 14 \\
\hline Industrias diversas & 43 & 20 \\
\hline \multicolumn{3}{|l|}{ Producción Primarla Intermedia (3) } \\
\hline Extracción de metales & 21 & 93 \\
\hline Petróleo y gas natural & 15 & 97 \\
\hline Extracción de carbón & 23 & 87 \\
\hline Agricultura y bosques & 31 & 72 \\
\hline Eloctricidad & 27 & 59 \\
\hline Minerales no metálicos & 17 & 52 \\
\hline \multicolumn{3}{|l|}{ Producción Primarla Final (4) } \\
\hline Pesca & 24 & 36 \\
\hline Transporte & 31 & 26 \\
\hline Servicios & 19 & 34 \\
\hline Comercio & 16 & 17 \\
\hline
\end{tabular}

Fuente: Chenery-Watanabe, reproducido por Hirschman (1964, p. 126).

Notas: (1) Las industrias manufactureras intermedias tienen ambos coeficientes elevados.

(2) Las industrias manufactureras finales tienen elevado coeficiente río arriba y débil coeficiente río-abajo.

(3) La producción primaria intermedia tiene débil coeficiente río-arriba y elevado coeficiente río-abajo.

(4) La producción primaria final tiene ambos coeficientes débiles. 
hoy ausentes, trasladamos un cuadro nacional que tiene cierta similitud con el de Chenery-Watanabe y Hirschman. Este es el cuadro 8. Sustituimos la primera columna de coeficientes río-arriba por el número de sectores de quienes la rama analizada demanda insumos; y sustituimos los coeficientes río-abajo por el número de sectores a quienes la rama analizada ofrece productos en transformación. De los 44 sectores presentados en la primera edición de la matriz insumo-producto-1978, en el cuadro 8 se listan aquellos sectores que destacan más como demandantes o como oferentes de insumos, pudiendo adicionar ambos efectos dinamizantes.

\section{Cuadro 8 \\ Sectores dinamizantes como demandantes $y$ oferentes de insumos}

\begin{tabular}{|l|c|c|}
\hline $\begin{array}{c}\text { Categoría del Sector } \\
\text { Productivo }\end{array}$ & $\begin{array}{c}\text { No. de sectores } \\
\text { demandados }\end{array}$ & $\begin{array}{c}\text { No. de sectores } \\
\text { servidos }\end{array}$ \\
\hline - Productos alimenticios & 42 & 29 \\
- Textiles & 33 & 42 \\
- Construcción & 31 & 23 \\
- Comercio & 23 & 38 \\
- Refinería Petróleo y derivados & 23 & 48 \\
- Transporte y almacenamiento & 36 & 46 \\
- Otros productos químicos & 34 & 43 \\
- Sustancias químicas e industrial & 25 & 43 \\
- Granos básicos & 15 & 6 \\
- Algodón & 28 & 3 \\
- Avicultura & 27 & 5 \\
- Restaurantes y hoteles & 22 & 35 \\
- Prendas de vestir & 34 & 33 \\
- Productos metálicos (no máquinas) & 33 & 44 \\
- Ganadería & 25 & 3 \\
- Bienes inmuebles y servicios & 27 & 41 \\
- Banca y Seguros & 32 & 46 \\
- Minas y canteras & 21 & 28 \\
- Papel y productos de papel & 30 & 42 \\
- Industrias básicas de hierro-acero & 19 & 33 \\
- Productos minerales no metálicos & 33 & 43 \\
\hline
\end{tabular}

Nota: el orden de los sectores responde al valor monetario de los insumos demandados y ofrecidos más que al número de sectores.

Los coeficientes de interdependencia del primer cuadro, o el número de sectores demandados o servidos del segundo cuadro, son índices aproximados del potencial dinamizante de los sectores económicos, pero con una notoria diferencia en ambos casos. Los paises industrializados tienen una malla interna más cerrada con recursos propios, mientras 
que la nuestra se sustenta en un elevado porcentaje de insumos y equipo importados.

Una segunda razón para decir que todos estos coeficientes son índices aproximados de la capacidad de dinamización es porque aquí sólo se consideran los efectos dinamizantes sobre los abastecedores directos de la rama analizada; pero estos primeros abastecedores, a su vez, tienen que pedir insumos a otros abastecedores en una cadena secuencial, originando nuevas relaciones intersectoriales. Es esto lo que mide la última sábana de nuestra matriz de 1978 como coeficientes técnicos invertidos, dato que también sirve para programar los requerimientos de producción sectorial en los planes quinquenales de desarrollo.

Comentando Hirschman los efectos dinamizantes rio-arriba, o sobre abastecedores, hace la siguiente consideración, muy a nuestro caso:

La falta de interdependencia y de relaciones es naturalmente una de las características esenciales de las economias subdesarrolladas. Si poseyéramos los datos insumo-producto homogéneos de todos los países sería instructivo clasificarlos de acuerdo a las transacciones intersectoriales respecto a la producción final; es probable que esta clasificación haría aparecer una estrecha correlación entre el ingreso per cápita y el porcentaje de la población ocupada en la industria (Hirschman, 1964, pp. 128-129).

Esta consideración nos lleva a los efectos beneficiosos que puede generar la tecnología y a los efectos perniciosos que la especialización en la producción mundial ha ido generando el mercado internacional. Comparando los dos cuadros matriciales, y dados los diversos niveles de desarrollo tecnológico, podemos observar que los países industrializados logran mantener y defender al interior de sus economias los sectores productivos en su fase de mayor dinamización, privando con ello a los paises en desarrollo de iniciarse en la creación de sectores dinamizantes, los cuales producen productos cuasi-terminados y transformados en los primeros paises.

Suele afirmarse, dirá Hirschman, que la agricultura es inferior en productividad a la industria; pero esto no es dél todo cierto. Es cierto en el caso de una agricultura de subsistencia y de métodos muy primitivos que no origina encadenamientos hacia abastecedores de insumos modernos. Es más dinamizante si la agricultura se moderniza y genera una demanda de semillas mejoradas, abonos, insecticidas, equipo..., que hoy por hay lo importamos. Pero la pérdida del poder dinamizante de nuestro sector agrario, en sentido amplio, radica en que se nos ha inducido o forzado a exportar la mayoría de productos agropecuarios en su estadio primitivo, sin mayor transformación, reservándose los países industrializados las fases más dinamizantes de transformación de los pro- 
ductos primarios. Algunos de ellos regresarán a nuestros supermercados más elegantes con embaces y lengua extranjera.

Adicionalmente, el hecho de que tales exportaciones tradicionales generaban divisas y buena rentabilidad a los grandes productores-exportadores, privaban de espacio adecuado y tecnología apropiada a los productos básicos alimentarios que las empresas multinacionales los harán sustituir en los supermercados por productos más sofisticados y más caros, sustentados en una publicidad generadora de gustos modernizantes y nombres extranjeros. Sobra decir que nuestras exportaciones tradicionales las vendemos en un mercado de compradores que nos asignan los precios y las cuotas, cuando hay cuotas asignadas. La ley de la oferta y demanda nos domina en este caso.

Aunque somos un país pobre en recursos minerales del subsuelo, vale la pena recordar la animada versión que en los paises del Tercer Mundo se generó en contra de las industrias "enclave" montadas en estos países. Se trataba de poderosas firmas extranjeras que explotaban y transformaban al interior de los paises pobres los minerales o recursos naturales (petróleo) como materia prima o intermedia de ulteriores transformaciones en el pais central. En las cercanías tenemos el caso de las "bananeras", mientras que en el resto de países la mayoria de estos "enclaves-primarios" se han nacionalizado o apropiado por nacionales. Lo que más nos puede interesar en nuestro caso son las "industrias enclaves de importación", que inicialmente no generan ningún efecto dinamizante ni río-arriba ni río-abajo. Se trata de empresas extranjeras 0 algo mixtas que introducen un bien o servicio final terminado o cuasiterminado.

Este es el caso típico de muchos productos alimenticios que se van introduciendo en la dieta de la población por efecto-imitación. Pueden tener un cierto efecto beneficioso en cuanto requieren de un complemento de valor-agregado: mezclas, empaques, embaces... antes de pasar al mercado final. Incluso en algunos paises se ha ascendido desde el supermercado (cerveza, productos alimenticios, vestidos...) hasta el sector primario sembrando la cebada-lúpulo, granos básicos y fibras naturales requeridas para el bien final. En otros casos, ese bien final a base de insumos externos se convierte en competidor de sucedáneos nacionales, reduciendo su capacidad de dinamización iitterna. Aquí juega mucho la publicidad que cataliza el efecto-imitación de géneros de vida importados.

Dado que el progreso tecnológico y el efecto-dominación (F. Perroux) ha hecho que los paises industrializados se concentren en las fases de transformación más dinamizantes de las economías, relegando a los 
países en desarrollo los extremos iniciales y finales donde estos efectos son más débiles, las sendas o vias del crecimiento y de la aplicación tecnológica parecen arrancar de ambos extremos por transformaciones sucesivas río-abajo de lo que exportamos o no utilizamos en su estadio primitivo, o bien introduciéndonos río-arriba por sucesivas transformaciones de bienes finales o cuasi-finales importados. Estas sendas del desarrollo tendrán mayor viabilidad si las programamos a nivel centroamericano, tanto por la necesidad de complementar recursos naturales como por la necesidad del trabajo en equipo requerido en estas investigaciones e innovaciones tecnológicas. Adicionalmente, las matrices intersectoriales de otros países algo más avanzados -columna de coeficientes técnicos de producción - nos pueden ensefiar a producir nuevos productos y con nuevas tecnologias. Por ello el BCR nos hará un buen servicio cuando edite las matrices insumo-producto de años más recientes.

Para iluminar el camino de ambas sendas del desarrollo, tanto W. Leontief, iniciador de las matrices intersectoriales, como Chenery citado por Hirschman, recomiendan realizar la "triangulación de la matriz". Un intento aproximado lo realizamos con nuestra matriz de 1978, a modo de somera aproximación de nuestra malla productiva con muchas lagunas (Véase Alvarado Pineda, pp. 148-157). La operación se simplifica con la ayuda de la computadora. La triangulación de la matriz consiste en ordenar, en columna vertical, los sectores productivos de los más a los menos demandantes de insumos al conjunto de ramas económicas. Aparecerá un triángulo más o menos perfecto, donde en la cúspide izquierda se sitúan los sectores más demandantes, a continuación los sectores menos o poco demandantes de insumos del conjunto económico. Normalmente, en la base inferior de dicho triángulo y en forma de filas horizontales aparecerán los sectores más demandados o más oferentes de insumos al resto de sectores.

Con la triangulación obtenemos una descripción del proceso productivo: en la cúspide del triángulo se sitúan los sectores finales (más demandantes de insumos). En la base los más oferentes o sectores primarios del proceso productivo, quedando en el centro del triángulo los sectores intermedios oferentes de los de arriba y demandantes de los de abajo. Se puede contemplar asi el triángulo o invertirlo, de manera que en la parte superior aparezcan los sectores por donde se inicia el proceso productivo, luego los intermedios y abajo los sectores de los toques o servicios finales. Como el proceso económico sigue la secuencia de sector primario, sector secundario y sector terciario, la figura más perfecta 0 más hundida que presente dicho triángulo muestra la presencia o la ausencia de relaciones intersectoriales del primario-secundario-terciario, asi como la extroversión de la economía vía exportaciones primarias. En 
el ensayo de nuestra triangulación matricial, el triángulo se transformó en una hamaca bien hundida semejante a la forma de nuestra "curva de Lorenz". Dos datos de economía subdesarrollada que requieren tanto el desarrollo hacia dentro como el desarrollo hacia fuera.

Si combinamos estos aportes con otras investigaciones sobre necesidades básicas y reactivación de la economía (Véase Orellana y Alfaro, 1987, e Ibisate, 1991), se cuenta con unos datos bastante reales para afirmar, por una parte, que la satisfacción de las necesidades básicas (canasta básica) puede convertirse en elemento internamente dinamizante de la economía y, por otra parte, que tenemos posibilidades a nivel nacional y sobre todo regional de realizar una serie de transformación río-abajo de productos primarios que, además de generar cierto dinamismo interno, generarian nuevos componentes de exportaciones no tradicionales. Fuera de los ejemplos que se citan en estos artículos e investigaciones, sin duda existen archivados en el silencio de las bibliotecas otros ejemplos apropiados fruto de investigaciones de tantos departamentos de ingeniería, administración de empresas o economia... Es la hora de sacar al mercado estos inventarios ociosos...

Bajo el título Democracia sin pobreza, Eduardo Stein y Salvador Arias Penate, de CADESCA, han reunido un conjunto de trabajos en los que se presenta una "alternativa de desarrollo para el istmo centroamericano". Es el resultado de un conjunto de investigaciones seriamente avaladas, que profundizan y concretizan científicamente la articulación agricultura-industria como línea de desarrollo hacia dentro y hacia fuera, a nivel nacional, regional y de integración en el mercado internacional:

El elemento 'bisagra' que vincula y potencia las relaciones recursos productividad, gente-naturaleza, sociedad-Estado, mercado interno-mercado externo, trabajo, industrialización, formación profesional, tecnologia, inversión, infraestructura, comercio, energía y medio ambiente, está en la articulación agricultura-industria, o en el proceso de industrialización de la agricultura, que es la tesis que en este volumen se explora (Stein y Arias Peñate, 1992, p. XI).

En el capítulo primero de este libro, donde se delinean los puntos de la estrategia alternativa, Salvador Arias Pefiate (1992, pp. 26-27) senala los siguientes ejes básicos:

En contrate con lo arriba esbozado, el presente estudio y el conjunto de trabajos al que este estudio pertenece, sustenta la proposición que se debe implementar en el istmo Centroamericano una estrategia económica distinta a la que se aplica actualmente, en la cual los intereses de estas sociedad sean la razón de ser de su propia economía. Los ejes básicos que sustancian dicha proposición son:

a) La transformación productiva y estructural de la agricultura regional (abun- 
dante en recursos agrícolas, ganaderos, forestales y pesqueros a nivel marino y continental) los cuales, con la modernización agrícola de la segunda mitad de este siglo, han estado sometidos a una explotación irracional y destructiva; cosa que se corresponde - desafortunadamente- con una población rural significativa pero empobrecida.

b) El fomento de la industrialización, tanto de esta agricultura, como de la pesca y de los insumos y servicios para ambas, con el fin de producir para el mercado interno-regional y para el mercado internacional (con base en una eficiencia que no descanse en la sobreexplotación de los recursos naturales y del hombre).

c) El logro de la Seguridad Alimentaria regional, mediante el fomento de la complementariedad entre producciones nacionales y el desarrollo de un Sistema Agroalimentario Regional, lo cual tiene como premisa básica el desarrollo de los mecanismos de acceso a los alimentos para toda la población. Esto último debe significar, además de una política estratégica y agresiva de generación de empleo y de una remuneración adecuada, políticas de redistribución del ingreso a la vez que promoción y desarrollo de pequeños y medianos productores de bienes y de servicios.

El conjunto de estudios del libro, ordenadamente integrados, se presentan como una alternativa complementaria y correctiva del modelo de ajuste estructural desde el contexto regional y mundial de la estrategia alternativa de desarrollo del Istmo Centroamericano, pasando por las rutas más importantes y las bases para generar el desarrollo alternativo, finalizando con el análisis del financiamiento y cooperación del proyecto. Si el mercado internacional de los países industrializados se caracteriza, no sólo por sus grandes avances tecnológicos, sino por ser un mercado integrado por bloques poderosos y donde sigue privando el proteccionismo de la producción nacional y las subvenciones a las exportaciones agrícolas, con una fuerte intervención estatal en la planeación estratégica y en la defensa de los intereses de sus electores nacionales, no resulta equitativo que el modelo neoliberal del ajuste se nos quiera imponer a simple nivel de pequeños países individuales, asentados en productos de sobremesa sin mayor transformación interna, sometidos a los ciclos de las exportaciones primarias y a múltiples trabas del mercadeo internacional.

Puesto que el mercado internacional no es un mercado de competencia perfecta, sino muy imperfecta, controlada y protegida, el modelo neoliberal de una inserción directa e individual en el comercio internacional continuará agravando nuestra debilidad estructural. Los datos bibliográficos y estadísticos, las rutas y ejemplarización concreta de la integración agricultura-industria y de la integración nacional-regional-internacional muestran que si existe un modelo alternativo, complementario y correctivo del impuesto por las instituciones financieras internacionales (FMI, 
BIRF, BID, AID...) a nuestra región. Esto significa que todo el esfuerzo de la ciencia y tecnología que propone impulsar el actual gobierno será función e irá dirigida a consolidar el modelo que mejor responda a nuestro desarrollo nacional-regional, como plataforma para entrar en el mercado internacional.

\section{Los programas de ciencia y tecnología}

En el trabajo arriba citado, el Dr. Hodara sostiene:

"Las revoluciones científicas y tecnológicas que presiden a la posindustrialización de las naciones de alto ingreso implican retos para los países rezagados. O se ajustan a ellos o salen de este juego competitivo. Por otra parte, la recuperación de la economía nacional y del bienestar social sólo son obtenibles a través de incrementos dinámicos de los factores productivos y la movilización de la comunidad científica (Hodara, 1992, p. 9).

El desafío tecnológico implica un reto, no sólo a la empresa particular, sino a la economía nacional y al bienestar social. El empresario innovador de Schumpeter debe ser toda la nación movilizada como una comunidad científica. El problema es que nos hallamos dentro de una economía de mercado, donde las innovaciones tecnológicas son el arma secreta para asegurar la supervivencia y el éxito de la empresa privada. Una vez más: ¿tecnología para quién y al servicio de quién?

Los enfoques de los programas tecnológicos presentarán diversos niveles de aplicación. FUSADES, al tratar el tema del sector público y privado en la posguerra, presenta este problema dentro del quehacer nacional tecnológico:

Por otro lado también debe protegerse la propiedad industrial a través de patentes de diseños, registros de modelos, de marcas, de avisos comerciales y de cualquier otro secreto industrial que represente un patrimonio para las empresas que se dedican a invertir en mejorar productos y técnicas de producción y venta. Esta ley puede promover la actividad inventiva de las empresas en los procesos y en los productos y, por lo tanto, favorecer el desarrollo tecnológico (FUSADES, 1992b, p. 9).

Podemos leer este párrafo desde la perspectiva histórica donde el progreso tecnológico se presenta como un proceso de creación destructiva; quien inventa e innova crea algo nuevo convirtiendo la rutina en recuerdo del pasado. FUSADES (1992b) indica que esta propiedad industrial debe ser fruto de la propia creatividad y libre competencia, y no un derivado de la competencia desleal o distribución exclusiva.

En los tratados de ciclos económicos se integran diversas explicaciones sobre la evolución tecnológica y cada una trata de apoyarse en 
argumentos históricos. Dado que la historia económica ha venido recorriendo todas las fases cíclicas, se podrá decir que la propia contracción y crisis de los mercados ha obligado a las empresas a una racionalización interna, desprendiéndose de todos los factores físicos y humanos obsoletos para concentrarse en los más productivos. La crisis forzaria la innovación de nuevos productos y nuevos métodos. Este sería el momento del empresario innovador, que tiende a arrastrar a otros empresarios en la línea de la renovación. Al entrar en la fase de recuperaciónexpansión, los inventos tienden a generalizarse, y en la prosperidad se vuelve a incrementar la demanda de todos los factores de producción. La siguiente recesión volvería a requerir una nueva racionalización de manera que a lo largo del ciclo las empresas repiten los movimientos de sístole y diástole del corazón humano.

Para otros autores, ya pasó el tiempo de los inventos-innovaciones de una mente privilegiada; hoy día el avance tecnológico es fruto de un tesonero trabajo en equipo de muchos investigadores e instituciones gubernamentales, empresariales y universitarias. Los mismos Estados, no sólo por razones de guerra, se han convertido en grandes demandantes de adelantos técnicos. Además, estamos pasando de los inventos particulares a las innovaciones "en racimos", en un proceso donde los objetivos tecnológicos se programan con antelación. Sin recurrir a más teorías, podemos concluir que la tecnología nace de la ciencia, y de una ciencia gestada por la comunidad científica gubernamental, empresarial y universitaria. Nuestro problema es que nos hallamos simultáneamente en crisis económica y en crisis de comunidad científica nacional.

Si en base a la ciencia y a la tecnología se distinguen y se separan los países industrializados de los atrasados, los ricos de los pobres, esta misma brecha diferencial la tenemos al interior de nuestros países por el hecho de que la educación es todavía un privilegio de minorías. Es lógico que tanto el programa de ciencia y tecnologia como la citada publicación de FUSADES enfoquen este problema, no sólo desde los avances tecnológicos empresariales, sino también desde la formación del capital humano nacional. En caso contrario, la tecnología profundizaría aún más la discriminación social si todo el proceso se redujera a sustituir al hombre por la máquina. Dado que en realidad el progreso tecnológico lleva a reemplazar el equipo o el método obsoleto por el innovador, la renovación humana se impone, no sólo a nivel del técnico profesional, sino a la totalidad de la mano de obra, pensando desde ya en ese cincuenta por ciento de la población menor de los 16 anos. Se impone toda una reestructuración del presupuesto estatal con miras al gasto social; se impone una decidida acción del Estado y de sus instituciones públicas (educación, salud...), así como de la comunidad privada en pro de la formación 
del capital humano; la tecnología, a secas, tiende a favorecer al otro capital.

La traducción real que se dé a los programas de ciencia y tecnología dependerá del modelo teórico que regule nuestro desarrollo económico. Cuando el eje de dicho creçimiento se ha basado en las exportaciones tradicionales, generadoras de divisas, la tecnología no perfeccionó en nada a los cultivadores directos de tales exportaciones. Ese modelo agroexportador ha generado desde antiguo una gran deseconomia 0 costo social, manteniendo a la mano de obra campesina alejada de toda tecnología. La simplicidad del equipo y de las operaciones manuales requeridas a lo largo del proceso productivo y de la fase final de la cosecha preferenciaban una población iletrada y asentada en "la civilización del machete". El costo social ha sido enorme al forjar un círculo vicioso de baja productividad, bajos salarios, baja formación profesional, para regresar a la baja productividad. Si el eje económico se vuelve a concentrar en las exportaciones tradicionales y no tradicionales, de la misma estirpe primaria y primitiva, continuaremos manteniendo una balanza comercial y una balanza tecnológica deficitarias. También por esta razón se necesita un modelo económico alternativo sustentado en un programa nacional de tecnologia.

Esta es la propuesta sostenida en la publicación de CADESCA arriba citada:

En el mundo contemporáneo la competitividad radica cada vez más en el progreso técnico -disminución de costos y aumento de la productividad -es decir, la exportación y sustitución de importaciones con alto valor agregado. Esto lleva la necesidad impostergable de una estrategia regional y, dentro de cada país, del desarrollo de la ciencia y tecnología. Este principio significa actuar, entre otras cosas, sobre: 1. La democratización del conocimiento y la información, dado que ésta es hoy norma estratégica de la organización del poder en la sociedad; por lo cual, los mismos no pueden - ni deben- estar controlados por grupos reducidos de la sociedad, y menos por instituciones o personas no nacionales. Es bajo esta visión que los sistemas nacionales de educación formal e informal tienen que pasar a ser un aspecto central de la planificación estratégica, como un patrimonio nacional necesario de desarrollar de manera acorde con las necesidades de la sociedad como un todo, en su quehacer interno e internacional. 2. La deficiente situación educacional de la población y las profundas modificaciones que se dan en los requerimientos educativos relacionados con el desarrollo económico (dadas las transformaciones en el conocimiento de la sociedad moderna) exigen que este rubro pase a ser más que nunca un elemento a impulsar de manera estratégica en el conjunto de la sociedad. No es posible pensar en implementar una estrategia centrada en las exportaciones, sin sistemas nacionales de educación que capaciten a la población involucrada en las exigencias que ésta requiere. Esto es más cierto para la estrategia alternativa aquí propuesta, en la cual se busca que la inmensa 
mayoría de micro, pequeños y medianos productores constituyan una base importante del desarrollo... (Arias Peñate, 1992, pp. 107-108).

Con los puntos suspensivos, tanto el Dr. Arias Pefiate como el Dr. J. Hodara, reclaman la necesidad de desarrollar la ciencia y la investigación básica en orden a generar tecnología aplicada:

La ciencia y la tecnología se apoyan mutuamente en el método experimental; la búsqueda de innovaciones técnicas se inspira con frecuencia en teorías propuestas por hombres de ciencia, en tanto que la ciencia utiliza aparatos y equipos producidos por los ingenieros. Se trata de variables transversales, que cortan a los sistemas culturales y productivos (Hodara, 1992, p. 10).

Esta afirmación de J. Hodara la encontramos entre las propuestas de S. Arias Pefiate (1992, p. 108):

Se ha considerado ilógicamente que las economías pobres no deben hacer investigación básica, dado que ésta se ha perfilado siguiendo el marco científico de los países desarrollados (por lo cual el imitarlos es un absurdo, además de imposible por las necesidades de recursos que esto requiere). No obstante, es determinante y necesario capacitar científicos en las ciencias básicas para desarrollar investigaciones propias, con la orientación de generar para la región capacidades científico-técnicas que nos permitan acceder y manejar los avances más modernos, sin negar la posibilidad de generación científica.

Entrecruzando propuestas dignas de tomarse en cuenta por nuestras universidades, el Dr. J. Hodara concreta los objetivos de la política científica·

Mejorar y ampliar la formación y la dotación de recursos humanos. Cabe estudiar e identificar qué ramas del saber deben ser incrementadas con el fin de apuntalar las transformaciones que se procuran, con una visión estratégica. Unir y articular la actividad científica nacional con los flujos mundiales del conocimiento, propósito que implica la constante revisión de programas docentes y de investigación, el acceso fluido a bancos de información y la participación activa en la creación de este conocimiento. Contribuir al entendimiento de las realidades y problemas nacionales más allá de las fronteras tradicionales entre las disciplinas científicas; de esta manera la ciencia probará su utilidad social y no sólo la legitimidad intelectual que le confiere en los centros avanzados de investigación (Hodara, 1992, pp. 10-11).

En concreto, esto requiere que los centros de ensefianza superior, sin perjuicio de su autonomia institucional, ayuden a entender y resolver los problemas nacionales; que se haga un inventario actualizado de los equipos disponibles, evaluar su óptimo empleo y modernización, así como obtener recursos externos de organismos multilaterales y fundaciones científicas para apoyar nuestras investigaciones, una vez se demuestre su calidad científica. Internamente, esto requiere una evaluación de la excelencia académica y una integración de equipos investigadores 
con el apoyo de fondos gubernamentales.

La transferencia de tecnología genera un nuevo rango de dependencia internacional; esto requiere la conformación de una política que balancee la dependencia externa con la equitativa autonomía tecnológica nacional-regional:

La nueva ciencia y tecnología del mundo se desarrollan en un esquema institucional que tiende a privatizar el conocimiento. Los paises más industrializados regulan la propiedad intelectual desde los intereses de sus empresas nacionales y transnacionales, que introducen en una legislación internacional -que después los países pobres se ven obligados a aceptar- sin darse cuenta o conocer los efectos positivos o negativos que esto pueda significar. Los países de la región deben definir una política sobre esta temática, de tal manera que los acuerdos que acepten o promuevan no les resten la posibilidad organización y/o desarrollo de un sistema científico-tecnológico propio, que responda a sus necesidades y les permita traducir en factor de riqueza económica y en ventaja sus recursos genéticos. Un principio tecnológico de este tipo pasa por la necesidad de crear las condiciones necesarias, dentro de las cuales se destacan la definición de políticas orientadas a la creación de líneas de financiamiento de capital de riesgo y el incentivo de joint-venture para el desarrollo científico-técnico y la producción masiva de las nuevas tecnologías. En este apartado el Estado tiene que jugar un papel estratégico (Arias Peñate, p. 109).

Dentro de la perspectiva del modelo de ajuste estructural, comentando el papel del sector privado, FUSADES (1992b) destaca la transcendencia de la inversión y la tecnología, siendo el crecimiento económico función de ambas variables, al mismo tiempo que toda la población se beneficia con la modernización empresarial. Se renueva la fe en el programa del ajuste, por estar creando "un ambiente de libertad económica, apertura comercial y competencia que trae nuevos retos y desafíos a las empresas privadas, las cuales deberán modernizar sus estructuras productivas y expandir sus inversiones". En la introducción de FUSADES (1992b) se deja entrever que no siempre la libre competencia es una competencia libre y requiere una regulación:

La competencia interna y externa ofrece los incentivos adecuados que permiten a las empresas desarrollarse en un libre mercado regulatorio que asegure su funcionamiento, el cual el Estado puede proveer. Además, en ciertas circunstancias el funcionamiento del mercado es deficiente".

Sin detenerse, en este momento, a desarrollar más detenidamente las imperfecciones del mercado nacional o internacional, se subraya

la significativa contribución que puede realizar el capital foráneo en las inversiones que el país necesita en su proceso de reconstrucción nacional. La inversión extranjera está llamada a convertirse en uno de los pilares de esta estrategia de crecimiento hacia fuera, a través de la introducción de nuevas tecnologías y 
técnicas administrativas, el desarrollo de proyectos de exportación no tradicionales y la apertura de nuevos mercados extranjeros para que el país pueda colocar eficazmente sus productos exportables... (FUSADES, 1992b)

Es claro que, hablando del mismo tema, la inversión-tecnología y la modernización exigida por el desafío internacional, difieran los enfoques y las políticas concretas, presentados el citado trabajo de FUSADES, de las medidas más ampliamente desarrolladas en el conjunto de trabajos integrados bajo el título de Democracia sin pobreza. Al fin y al cabo, se trata de modelos económicos alternativos, que merecen su conocimiento y ponderación.

Factor positivo del planteamiento de FUSADES (1992b) es el acápite dedicado a la capacitación y adiestramiento laboral, como un deber de la empresa privada:

En este sentido, el papel que debe jugar el sector privado es el de implementar y poner en marcha al interior de sus respectivas empresas programas de capacitación y adiestramiento para sus propios trabajadores, de tal modo que ellos puedan aprender el uso de la tecnología moderna que se está incorporando en la economía (p. 11).

Por ello, se solicita la creación de programas conjuntos y compartidos con el gobierno para instaurar este sistema de aprendizaje en las empresas, con salarios menores y aporte parcial del gobierno. También se requiere una mayor vinculación del sector productivo y los institutos tecnológicos y universidades con miras a un proceso de mutua retroalimentación, así como por el impacto que ellas tienen en la formación de capital humano de la sociedad.

Dado el rezago tecnológico en que, por tantas razones nos hallamos, y por otra parte la urgencia de avanzar en forma integrada, la acumulación de nuevas propuestas sef́alan al mismo tiempo nuestras deficiencias y nuestros desafíos. Estando situados en el escenario del Plan de Reconstrucción Nacional y en las expectativas del Foro de Concertación Económico-Social, vale la pena - como última cita - trasladar algunas medidas concretas que parecen delinearse en el programa de ciencia y tecnología ministerial:

Orientar los recursos destinados a las innovaciones técnicas en favor de los sectores sociales menos favorecidos, especialmente a aquellos que han sufrido las consecuencias de los ajustes estructurales a las crisis económicas y del conflicto armado. Restaurar y mejorar el entorno ambiental que ha resentido impactos negativos en la última década. Alentar los empalmes entre las diferentes etapas de la innovación, incluyendo las labores de gestión, gerencia, evaluación y normalización. Estos vínculos aceleran la difusión social y productiva de las innovaciones. Vigilar que los subsidios que se ofrezcan al desarrollo de nuevas técnicas conocidas sean transitorios y se justifiquen con transparencia. 
Estos subsidios no deben disimular errores o ineficiencias. Promover la creación de laboratorios industriales dentro de las empresas, con el objeto de que respondan a las necesidades de corto y mediano plazo con arreglo a la planeación corporativa. Condicionar las inversiones extranjeras a una derrama tecnológica significativa en la fuerza laboral, y al establecimiento de centros de adiestramiento que afiancen el desarrollo manufacturero. Propiciar la adaptación de tecnologías importadas a través de los mecanismos administrados por el Gobierno, como los financieros, fiscales, arancelarios, y los normativos de transferencia de tecnología y de la propiedad industrial (Hodara, 1992, pp. 13-14).

Gracias a la ponencia que el Dr. J. Hodara hiciera en su rápida e interesante visita a la UCA hemos tenido un conocimiento más preciso del Programa de Ciencia-Tecnología, preparado por el Ministerio de Economia y presentado a una primera rueda de sugerencias en varias instituciones universitarias y de investigación. En esta ponencia se esquematiza la estrategia del programa, el financiamiento de la modernización científica y tecnológica, la formación de recursos humanos, el marco jurídico y mecanismos institucionales, y finalmente las líneas generales para la puesta en marcha del programa. Nos quedamos a la espera de una detallada publicación oficial.

Es posible que toda esta temática de la renovación tecnológica aflore en el Foro de Concertación. El gobierno tiene su programa de Ciencia y Tecnología; el sector empresarial se inspirará normalmente en las publicaciones de FUSADES. Es más difícil adelantar la postura de las universidades y centros de investigación, por ser un conjunto bastante heterogéneo. Los gremios laborales estarán, sin duda, más de acuerdo con el título y el contenido de los análisis agrupados en la obra Democracia sin pobreza. Se trata de una alternativa para 1992 y para $1994 .$.

\section{REFERENCIAS BIBLIOGRAFICAS}

Abrego, L. (1991) "Los programas de ajuste del FMI: Contenido, bases teórico, analíticas y resultados". Realidad Económico-Social \# 23 (SeptiembreOctubre).

Alvarado Pineda, S. (1987). Análisis global de la matriz insumo-producto e identificación del modelo económico salvadoreño. San Salvador: Tesis de grado, UCA.

Arias Peñate, S. y J. Jované (1992). "La transformación e industrialización de la agricultura del Istmo Centroamericano como eje de una nueva estrategia de desarrollo", en Stein, E. y S. Arias, Peñate (eds.), Democracia sin pobreza: alternativa de desarrollo para el istmo centroamericano. San José: DEI/CADESCA.

Donis, J.A. (1988). Estructura y articulación agroindustrial en El Salvador. San Salvador: Tesis de grado, UCA. 
FUSADES (1991). Informe trimestral de coyuntura 1991, No. 3.

FUSADES (1992a). "Principales resultados de la balanza de pagos durante 1991". Informe oconómico semanal, 25-marzo-92. No. 13.

FUSADES (1992b). "El papel del Gobierno y del sector privado en la posguerra". Boletín Económico-Social \# 76 (Marzo).

Hirschman, A. (1964). Stratégie du dévelopement économique. París: Edit. Ouvrkières.

Hodara, J. (1992). Programa Nacional de Ciencia y Tecnología de El Salvador1992. PNUD/CEPAL/LPES. Proyecto ELS/90/004. Borrador.

Ibisate, F.J. (1991). "La construcción de posguerra y la construcción de la paz". Realidad Económica-Social \# 22 (Julio-Agosto), pp. 439-455.

A. Orellana, A. y N. Alfaro (1987). Necesidades básicas y reactivación de la economia. San Salvador: Tesis de grado UCA. 